\title{
Estudio familiar de asma bronquial extrínseca
}

\author{
Eliana Selman C. ${ }^{1}$ : Maria Mena R. ${ }^{1}$; Mariana M. Aracena ${ }^{2}$; Aldu Bancalari M..$^{3}$ \\ Frainé Nuñez ${ }^{4}$; Heberto Castro $P^{5}$
}

\section{FAMULAL STUDY ON EXTHINSIC ASTHMA.}

\begin{abstract}
The prevalence of bronchial asthma and atopy was studied in relatives (first and seend degrees) from 74 children with extrinsic bronchial asthma and from 90 children without bronchial asthrna The age of the children studied ranged from $21 / 2$ to 15 year old. Bronchial asthrua in children was diagnosed by clinical examination, prick skin test. blood eosinophils a cnunt and bronchial challenge with exercise test Bronchial asthma and atopy diagnosis in relatives was done by a questionaire and by a prick skin test.

We found a higher prevalence $(\mathrm{p}<0.01)$ in all the relatives of asmathic children (14.8\% for prarents), as compared to controls (3.9\% for parents) A stroilar difference in the prevalence of atopy was found only by comparing both, the parents and grand parents between the series. However we did not find significant differents in atopy between the two groups by comparing the other relatives. These results confirms the importance of inheritance in bronchial asthna. They suggest that ast thua and atopy are inherited similarly but independently. Atopy is not necesarily associated to asthma but enharces its phenotipic expression.
\end{abstract}

Estudios familiares anteriores sugieren una base hereditaria en el asma bronquial, ${ }^{6,7}$ especialmente en la de tipo extrínseca en que los individuos son atópicos y tienen positivos los test cutáneos a diferentes alérgenos. En la mayoría de ellos se demuestra una mayor prevalencia familiar

\footnotetext{
${ }^{1}$ Médico Servicio de Pediatría. Sección genética. Hospital GuiIlermo Grant Benavente de Concepción.

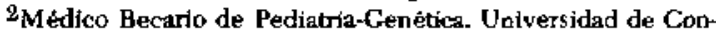
cepeíón.

${ }^{3}$ Médico Servicio de Pediatria. Hospital de Coronel.

${ }^{4}$ Bioquimico. Hospital de Coronel.

5 Profesor de Estadistica. Facuttad de Medicina Lniversidad de Cancepción.
}

de esta enfermedad. Además, estudios en mellizos mono y dicigóticos apoyan este componente genético, al encontrarse en todos ellos una mayor concordancia de asma bronquial en los monocigóticos comparados con los dicigóticos. ${ }^{1}$ Sin embargo, a pesar de la evidencia de la base hereditaria en el asma bronquial, su mecarismo de herencia aún no ha sido dilucidado.

Desde hace varias décadas se ha sugerido una estrecha relación entre asma y atopía, siendo esta última claramente mediada por factores genéti$\cos ^{2}$ Ya en 1916, Cooke encuentra una mayor agrupación familiar para manifestaciones de atopía. Esto ha sido reafimado posteriormente por 
otros investigadores. ${ }^{4}$ La mayoría de ellos demuestra un alto porcentaje de atopía en parientes de primer grado de niños atópicos.

Los objetivos de este estudio fueron determinar la prevalencia de asma bronquial $y$ atopía en los familiares de primero y segundo grado de nin̄os con asma bronquial extrínseca y de niños controles, y según resultados pastular posibles mecanismos de herencia de esta enfermedad.

\section{MATERIAL Y METODO}

Se estudiaron los familiares de primero y segundo grado de un total de 164 niños, de los cuales 74 tenían el diagnóstico de asma bronquial extrinseca, a quienes denominamos probandos asmá- ticos, todos los cuales fueron controlados en la Policlínica de Broncopulmonar del Hospital de Coronel. Los otros 90 niños constituyeron el grupo control a los que denominamos probando controles y fueron tomados al azar desde la Policlínica de niños y del Servicio de Urgencia del mismo Hospital; tenían similares caracteristicas con el grupo de niños asmáticos, pero no habían presentado ningín episodio bronquial obstructivo que hiciera sospechar la presencia de asma bronquial. El rango de edad para ambos grupos fue de $21 / 2$ a 15 años, con un promedio de 6.8 años para los probandos asmáticos y 8.3 para los probandos controles. En el grupo de asmáticos el 47,3\% eran mujeres y el 52,7 hombres. En el grupo control el $57,7 \%$ eran mujeres y el 42,3 hombres. (Tabla 1 ).

Tabla 1

ESTUDIO FAMILIAR DE ASMA BRONQUIAL EXTRINSECA

DESCRIPCION DE PROBANDOS

\begin{tabular}{|c|c|c|c|c|c|c|}
\hline \multirow[b]{2}{*}{ PROBANDOS } & \multirow[b]{2}{*}{ NA NINOS } & \multicolumn{2}{|c|}{ MUJERES } & \multicolumn{2}{|c|}{ HOMBRES } & \multirow[b]{2}{*}{$\overline{\mathbf{x}}$ EDAD } \\
\hline & & $\mathrm{N}^{2}$ & 8 & $\mathrm{~N}^{2}$ & 8 & \\
\hline $\begin{array}{l}\text { GRUPO ASMA- } \\
\text { TICOS }\end{array}$ & 74 & 35 & 47,3 & 39 & 52,7 & 6,79 \\
\hline $\begin{array}{l}\text { GRUPO CON- } \\
\text { TROL }\end{array}$ & 90 & 52 & 57.7 & 38 & 42,3 & 8,32 \\
\hline TOTAL & 164 & 87 & 53 & 77 & 47 & 7,55 \\
\hline
\end{tabular}

Todos los niños asmáticos tenian una historia de episodios bronquiales obstructivos que respondían parcial o totalmente a la administración de broncodilatadores. La radiografía de tórax practicada a todos ellos, apoyó el diagnóstico y descartó otra patología pulmonar. Otros exámenes compatibles con el diagnostico de asma bronquial fueron: eosinofilia nasal y sanguinea; test de provocación bronquial con carrera libre ${ }^{\vec{j}}$ y Prick-test positivo a dos o más alérgenos, considerándose positivo una pápula mayor de dos milímetros de diámetro.

El estudio familiar se basó en un interrogatorio efectuado a uno o ambos padres de los probandos. Este consistió, en un cuestionario en el cual se investigaba en los parientes referidos los siguientes datos:

1. Antecedentes de asma y atopía; considerándose como atopía a la rinitis alérgica, eczema y urticaria.

2. Número total y sexo de individuos sanos y afectados. Se realizó un Prick-test en los padres y hermanos accesibles con probable asma y/o atopía.

Para el análisis estadístico de los resultados se utilizó el test de Chi cuadrado $\left(\mathrm{X}^{2}\right)$. 


\section{RESULTADOS}

La prevalencia de asma y atopía en los parientes de probandos asmáticos y controles se esquematizan en las tablas 2 al 5 . Observanos que la prevalencia de asma bronquial en todos los parientes de los probandos asmáticos tanto de primer grado como de segundo, fue significativamente mayor, segín prueba de $\mathrm{X}^{2}(\mathrm{p}<0.01)$, que la encontrada en los parientes del grupo control. Se encuentra la mayor prevalencia de asma, en los padres de los niños asmáticos (14.9\%), comparada, con los padres de controles cuyo valor fue $3.9 \%$ (Tabla 2). En los hermanos la prevalencia de ambos grupos estudiados fue de $8.4 \%$ y $1.1 \%$ respectivanente (Tabla 3). En los abuelos y tios los resultados fueron significativos también (tablas 4 y 5 ).

Tabla 2

PREVALENCIA DE ASMA Y ATOPIA EN PADRES DE PROBANDOS

\begin{tabular}{|c|c|c|c|c|}
\hline \multirow[t]{2}{*}{ PROBANDOS } & \multicolumn{2}{|c|}{ PADFES ASMAIICOS } & \multicolumn{2}{|c|}{ PADRES ATOPICOS } \\
\hline & $N^{0}$ & $\%$ & $\mathrm{NO}^{\circ}$ & $\%$ \\
\hline GRUPO ASMAIICOS & $27 \% 148$ & 15,86 & $27 / 168$ & 2699 \\
\hline GRUPO CONTROL & $7 / 180$ & 3,80 & $151 B 0$ & 8,33 \\
\hline
\end{tabular}

Tabla 3

PREVALENCIA DE ASMA Y ATOPIA EN HERMANOS DE PROBANDOS

\begin{tabular}{|c|c|c|c|c|}
\hline \multirow[t]{2}{*}{ PROEANDOS } & \multicolumn{2}{|c|}{ HERMANOS ASMATICOS } & \multicolumn{2}{|c|}{ LERMANOS ATOPICOS } \\
\hline & $n^{\circ}$ & $\%$ & $N^{\circ}$ & $\%$ \\
\hline GRLPO $\triangle S M L I I C O S$ & $12 / 163$ & 8,39 & $16 / 6]$ & 9,79 \\
\hline GRLPO CONTROL & $2 / 786$ & 1.06 & $W: 188$ & 580 \\
\hline
\end{tabular}

Tabla 4

\section{PREVALENCIA DE ASMA Y ATOPIA EN ABUELOS} DE PROBANDOS

\begin{tabular}{|c|c|c|c|c|}
\hline \multirow[t]{2}{*}{ PROBANDOS } & \multicolumn{2}{|c|}{ ABUELOS ASMAIKOS } & \multicolumn{2}{|c|}{ ABUELOS ATOPICOS } \\
\hline & $\mathrm{N}^{\mathrm{a}}$ & $\because$ & $\mathrm{N}^{a}$ & $\%$ \\
\hline GRUPO ASMATICOS & $27 / 296$ & 9,12 & 26 & 8,10 \\
\hline GRUPO CONIROL & g/ 360 & 2,22 & $s$ & 2,5 \\
\hline
\end{tabular}

Tabla 5

PREVALENGIA DE ASMA Y ATOPIA EN TIOS DE PROBANDOS

\begin{tabular}{|c|c|c|c|c|}
\hline \multirow[t]{2}{*}{ PFOBANTOS } & 1105 & ASMAIICOS & Y105 & PICOS \\
\hline & $N^{0}$ & $\%$ & $N^{2}$ & $\%$ \\
\hline GRUPO ASMATICOS & 27776 & 3,5 & $167 \%$ & 2,06 \\
\hline GRUPO CONTROL & $9 / 777$ & i. 15 & $7 \pi 77$ & 0,9 \\
\hline
\end{tabular}

Tabla 6

PREVALENOA DE ASMA Y ATOPIA EN PARIENTES DE PRIMER GRACO DE PROBANDOS CON 5 O MAS PRUEBAS [UTANEAS $1+$ I Y CON MENOS DE* 5

\begin{tabular}{|c|c|c|c|c|c|c|c|}
\hline \multirow[t]{2}{*}{ PROEANDOS } & $\begin{array}{l}\text { PADRES } \\
\text { ASMAIICOS }\end{array}$ & \multicolumn{2}{|c|}{$\begin{array}{r}\text { PADRES } \\
\text { ATOPICOS }\end{array}$} & \multicolumn{2}{|c|}{$\begin{array}{l}\text { HERMANOS } \\
\text { ASMATICOS }\end{array}$} & \multicolumn{2}{|c|}{$\begin{array}{l}\text { HERM ANOS } \\
\text { ATOPICOS }\end{array}$} \\
\hline & $\mu \quad \%$ & no & $\%$ & $\mathrm{~N}^{*}$ & $\%$ & $N=$ & $\%$ \\
\hline $\begin{array}{l}\text { GRUPO ASMAII- } \\
\text { COS LON } 50 \text { MAS } \\
\text { ALRGEMOS (A) }\end{array}$ & $0 / 26 \quad 3076$ & $10 / 26$ & 3,46 & $2 / 25$ & B & $4 / 25$ & 16 \\
\hline $\begin{array}{l}\text { GUPO ASMAIN- } \\
\text { CES CON WENOSOS } \\
\text { O SALERGENOS }\end{array}$ & $14 / 127$ & $28 / 12 \pi$ & 182 & צ̧ג & +62 & $70 / 718$ & 847 \\
\hline
\end{tabular}

Para la atopia se observa algo muy simflar, los valores encontrados son muy semejantes a los que se encuentran en el asma, las diferencias al comparar la prevalencia de atopía en los parientes de ambas series, resultan estadísticamente significativas $(p<0.01$ ) para el grupo de los padres $y$ abuelos (Tablas 1 y 4 ), pero no resultan signíficativas para el resto de los parientes que serían los hermanos y tios (Táblas 3 y 4 ).

Se observó una mayor prevalencia $(\mathrm{p}<0.02)$ de asma en los padres de niños asmáticos que tenían 5 o más pruebas cutáneas positivas al compararlas con la de los padres de niños asmáticos con menos de 5 pruebas positivas (Tabla 6).

No se encontró diferencias de distribución por sexo ya que $46,6 \%$ de todos los parientes asmáticos eran de sexo masculino y el $53,4 \%$ femenino. El $45 \%$ de los parientes atópicos tenían sexo masculino y el $55 \%$ femenino.

\section{COMENTARIO}

Los resultados obtenidos en este estudio son similares a los encontrados en anteriores investigaciones. ${ }^{6,7}$ En los padres de los niños asmáticos, parientes de primer grado, se encontró la mayor 
prevalencia de asma, con un $14.9 \%$; y en los padres de los controles solamente un $4 \%$ (Tabla 2). Sibbald ${ }^{6}$ encuentra cilras muy cercanas a las nuestras, $18 \%$ y $4 \%$ respectivamente para los padres de ambas series.

En los hermanos de ambos grupos, la prevalencia de asma encontrada (Tabla 3), está también de acuerdo con los valores observados en el trabajo de Sibbald. ${ }^{6} \mathrm{Sin}$ embargo, pensamos que estas cifras son más bajas que las reales, dado que en alguno de los hermanos puede que aún no se haya manifestado la enfernedad, ya que muchos de ellos tenían menos de 2 años. Además, encontramos en varios la presencia de bronquitis obstructiva recidivante, que en un porcentaje importante evolucionan como asmáticos. ${ }^{4.9}$ Köning and Godfrey ${ }^{10}, 11$ demostraron que dos factores importantes en la patogénesis del asma, como el aumento de labilidad bronquial y la atopía son más frecuentes en familiares de niños con bronquitis obstructiva que de niños normales. Sibbald ${ }^{12}$ también sugiere un factor genético común para estas dos entidades.

La distribución de la prevalencia de atopía en los familiares estudiados de los niños con asma bronquial extrinseca, fue similar a la encontrada en el asma (Tablas 2 al 5), lo que está indicando un mecanismo de herencia similar. Por otra parte, el hecho de encontrar una mayor prevalencia de asma en los padres de niños atópicos a un mayor número de alérgenos (Tabla 6), sugiere una estrecha relación entre asma y atopía, relación que es apoyada por los trabajos de Sibbald y $\mathrm{Col},{ }^{7}$ quienes encuentran un aumento de la prevalencia de asma en los parientes de primer grado de probandos que presentan un mayor número de manifestaciones de atopía. Sin embargo, al comparar la prevalencia de atopía en los parientes de los niños asmáticos y de los controles, no se encuentran diferencias significativas entre los hermanos y entre los tíos; a diferencia de lo observado en el asma en que las diferencias fueron significativas en todos los grupos de parientes $(\mathrm{p}<0.01$ ). Estos sugieren que no habria una asociación permanente entre asma y atopía, apoyando la hipótesis de una herencia independiente, vale decir deterninada por diferentes genes. A su vez Köning and Godfrey ${ }^{13}$ demostraron que para ser asmático se debe heredar, además de atopía, otro tactor como sería una mayor labilidad bronquial. En base a estos resultados podemos decir que la atopia favorecería la manifestación de asma en individuos gené- ticamente predispuestos, es decir aumentaría la penetrancia de esta enfermedad.

Factores ambientales también tendrian una influencia en el desencadenamiento del asma. En 1939 Hara $^{14}$ hace una observación de la importancia de los factores exógenos, destacando que la fiebre de heno es prácticamente desconocida en el Japón, pero el 3,5\% de la población japonesa residente en Califomia Meridional U.S.A. presenta esta afección, hecho que el autor atribuye a las condiciones meteorológicas y botánicas del Japón. Paralelamente estudios en mellizos monocigóticos muestran una concordancia para el asma que va entre el 50 y el $80 \%$ según diferentes autores, ${ }^{1,}{ }^{15}$ lo que indicaría que habrian otros factores, además del factor genético en el mecanisino del asma.

Aún cuando en nuestro estudio no podemos asegurar el mecanismo de herencia del asma bronquial, nos permite postular, según nuestras observaciones y las de otros investigadores, dos posibles mecanismos. En primer lugar, planteamos una herencia autosómicua dominante con diferente penetrancia y expresividad, basada en la distribución familiar, puesto que se encuentran individuos afectados en todas las generaciones de una misma familia, siendo los parientes de primer grado los que tienen las mayores posibilidades de presentar esta enfermedad. Además, atopía y factores ambientales tendrian una acción en la penetrancia y en la expresividad. En segundo lugar planteamos una herencia poligénica, ya que la distribución familiar encontrada también es compatible con este tipo de herencia. Además Sibbald ${ }^{7}$ encuentra un aumento en la prevalencia de asma en los hijos de ambos padres asmáticos al compararla con la de los hijos de uno o ninguin padre con asma. Por otra parte Williarns ${ }^{16}$ observa que a mayor gravedad del asma, hay una mayor incidencia de esta enfermedad en los parientes de primer grado. Estos hechos tarnbién apoyarían este tipo de herencia. Al no encontrar diferencias en la distribución por sexo en el asma, tanto en los niños estudiados como en sus parientes, sugiere que este rasgo no sería ligado al sexo.

Finalmente, podemos decir que todos los estudios familiares de asma bronquial enfrentan ciertas limitaciones, debido a que la identificación del asma, fiebre de heno, eczema y otras manifestaciones de alergia, tienen algún grado de error. Además las características básicas del asma como serían la reactividad bronquial y los trastornos 
inmunológicos son dificiles de estudiar en todos los casos, lo que ha limitado un mejor conocimiento de la herencia en el asma.

\section{RESUMEN}

Se estudia la prevalencia de asma bronquial y atopia en los parientes de primer y segundo grado de 74 niños con asma bronquial extrínseca y de 90 niños controles que no presentan esta enfermedad. El rango de edad de los niños estudiados fue de 2 1/2 a 15 años. El diagnóstico de asma bronquial se hizo por un examen clinico; Prick-test; eosinofilia y test de reactividad bronquial con ejercicio. Asma bronquial y atopía se diagrosticaron en los parientes a través de una entrevista a uno o ambos padres y Prick-test a los familiares accesibles. Se encuentra una prevalencia significativamente mayor $(\mathrm{p}<0.01)$ en todos los parientes de los niños asmáticos ( $14.8 \%$ para los padres) al compararla con los parientes de controles $(3.9 \%$ para los padres). Diferencias simjlares encontramos en la prevalencia de atopía al comparar los padres y abuelos entre ambas series. Sin embargo, no encontramos diferencias significativas para los valores de la atopía en los hermanos y tíos de ambos grupos.

Estos resultados confirman un importante patrón hereditario en el asma bronquial. Ellos indican también, que asma y atopia son heredados en forma similar pero independientemente. Atopía no estaria siempre asociado al asma pero sí aumentaría la expresión fenotípica de esta enfertnedad.

\section{REFERENCIAS}

1 Charpin, d. and Ameud, A. Facteurs genettitues dans I'usthine et les allerpies respintoires. Le Poumon et le: Couer. 27, 111-119 (1971).

2 Morch D.G., Blos WB., shimker K. Genetic control of basal serum inmunoglobulin $\mathbb{E}$. level and its effects on specific: reaginic sensitivity. Proc. Natl. Acad. Sci. L.S.A. 71, 3,588-92 (1974).

3 Cooke, R.A, and Vander-Beer J.B.: Human sensitizacion. J. Inımun; 1.201 (1916).

4 Crits $G_{\text {. }}$ : Evidence for familial allergy a study of 50 children and their parents. Pediatrics. 27; 45-50 $(1961 \%$.

${ }^{5}$ Conolly, N and Godficy, S.. asseessment of the child with asthma, J. Asthmia Res 8; 31 \{1970).

6 Sibbald B., Hom E.C.; Bnain E. and Gregg I.: Genetic factors in childhood asthma. Thorax, 35; 671-674 (1980).

7 Sibbold B. Tumer-Worwick M.: Factors influencing the prevalence of astluma annong hirst degree relatives of extrinsic and intrinsic isthmatics Thorax, 34; 332-33i (1979).

$\therefore$ Boesen, J.: Asthmatic bronchitis in children. Acta Paed, 42; 87 (1953).

Y Williams $H$, and $M c$ Nkol, $K N$.: Prevalence, natural history and relationship of wheezy bronchitis and usthma in childreo. An epicleniulogical study. British Med. J. 4; $321-325$ ( 1969 ).

10 Köning, P. and Godfory, S. Exercise-induced brunchial lability and atopic status of families of infants with wheezy bronchitis. Arch I) is in Chil, 46; 942-946 (1973).

It Köning, P. Godfrey, S. and Abrahamov, A. Exercise-induced broncial lability in children with a history of wheesy bronchitis. Arch Dis in Chil, 47; 578-580 (1972),

12 Sibbald B., Hom M.E. Greggl. A. family study of the genetics of asthına and wheezy bronchitis. Arch. Dis. Child 55; 354-357 (1980).

${ }^{1.3}$ Koning, $P$. and Godfney, S. Prevalence of exercise-inducided bronchial lubility in families of children with asthrna, Axch. Dis. in Child., 48; 51.3-517 (1973).

14 Ham, H.J.: Hay fever among Japoneses, Arch. Otolaryng 30; $525\{1939\}$.

15 Edfors-Lubs ML. Allergy in 7.(OF) twin pairs. Acta Allergol. 26; 249-85 (197)).

16 Williams $H$, Phelan P.: La enlennedad respiratoria en los niñus. Salvat Editores. S.A. Mallorca pp.: 134-5 ( 1978 ) 